\title{
Arsenate and Arsenite Sorption on Carbonate Hosted Precious Metals Ore
}

\author{
David L. Decker,* Charalambos Papelis, Scott W. Tyler, Mark J. Logsdon, and Jirka Šimůnek
}

\begin{abstract}
The societal impacts of As in water resources in the arid western USA are potentially acute as a consequence of the combined effects of limited water supplies and the pervasive occurrence of naturally occurring As in subsurface geologic formations, including the carbonatehosted, disseminated gold-bearing formations of the Carlin Trend. The prevalence of As in secondary minerals in gold-bearing carbonatehosted ores is of interest because of the potential for As release as a result of ore development. A key component to gold mining is the engineering and construction of large-scale heap-leach and waste-rock containment structures that are characterized by variably saturated hydrology. Estimating As release behavior from these structures with a variably saturated reactive flow and transport numerical model requires the quantification of the significant differences in the sorption behavior for the stable redox states for As. Therefore, the objective of this study was to quantify this sorption behavior and to represent the observed behavior with an isotherm formulation. The pH-dependent sorption behavior of arsenite, As(III), and arsenate, As(V), onto two carbonate-hosted gold ores is presented. The experimentally determined pH-dependent sorption behavior for both $\mathrm{As}(\mathrm{III})$ and $\mathrm{As}(\mathrm{V})$ is consistent with sorption on metal oxides as reported in studies on rock and soils with similar bulk mineralogical properties. The experimental sorption data are represented with two modified isotherm formulations. Modified formulations of the Langmuir isotherm and of the Sips isotherm are presented that include the $\mathrm{pH}$ of the sorbate solution as an additional model parameter. These formulations are applied to both $\mathrm{As}(\mathrm{III})$ and $\mathrm{As}(\mathrm{V})$ sorption data to generate an isotherm surface. The pH-dependent isotherm methodology can be incorporated readily into numerical models for the purposes of estimating As transport behavior in field-scale, variably saturated environments.
\end{abstract}

A RSENIC is present in the environment in a variety of mineral and aqueous forms and is found throughout the USA (Welch et al., 2000). Arsenic can be toxic at moderate levels of $10^{-6}$ to $10^{-5} \mathrm{M}$ in natural and drinking water, thereby requiring treatment of this water to reduce the concentration of As to the drinking water standard of $10^{-6.87} M\left(10 \mu \mathrm{g} \mathrm{L}^{-1}\right)$. The state of Nevada is the largest producer of gold in the contiguous USA, producing more than $226800 \mathrm{~kg}$ ( 8 million ounces) per year from 179 ore deposits (Driesner and Coyner, 2000;

D.L. Decker, Desert Research Institute, 2215 Raggio Parkway, Reno, NV 89512 USA; C. Papelis, Desert Research Institute, 755 E. Flamingo Road, Las Vegas, NV 89119 and Water Resources Management Graduate Program, Univ. of Nevada, 4505 Maryland Pkwy., Las Vegas, NV 89154-4029 USA; S.W. Tyler, Dep. of Natural Resources and Environmental Sciences and Dep. of Geological Sciences and Engineering, MS 175, Univ. of Nevada, Reno NV 89557-0180 USA; M.J. Logsdon, Geochimica, Inc., 9045 Soquel Dr., Suite 2, Aptos, CA 95003 USA; J. Šimůnek, Dep. of Environmental Sciences, A135 Bourns Hall, Univ. of California, 900 University Ave., Riverside CA 92521 USA. Received 14 Mar. 2005. *Corresponding author (dave. decker@dri.edu).

Published in Vadose Zone Journal 5:419-429 (2006).

Original Research

doi:10.2136/vzj2005.0038

(c) Soil Science Society of America

677 S. Segoe Rd., Madison, WI 53711 USA
Price, 2000). Northeastern Nevada and small areas of western Utah contain the richest gold-producing region yet discovered in North America. This region is known as the Carlin Trend, and it contains several goldproducing ore types that are often combined under the moniker "Carlin-type." One of the characteristics of the Carlin Trend deposits is the co-occurrence of As mineralogy with gold (Tooker, 1985). Typically, gold is extracted from Carlin-type ores by large-scale, heap leaching of crushed ore using alkaline cyanide solutions. The prevalence of As mineralogy combined with the large-scale mining operations has led to concerns regarding the potential for release of As into surface water and groundwater resources not only during heap-leaching operations but also after mining due to long-term draindown of residual fluids or leaching by meteoric water infiltration.

The objective of this work was to determine the $\mathrm{pH}$ and oxidation state-dependent sorption behavior of $\mathrm{As}(\mathrm{III})$ and $\mathrm{As}(\mathrm{V})$ on two representative samples of Carlin Trend ores. In turn, the sorption behavior will be integrated into a variably saturated reactive transport model to simulate As release and transport from heapleach facilities. This model will be used to facilitate the design and evaluation of long-term As mitigation strategies for heap-leach facilities. The need for experimental sorption data and a mathematical formulation to describe $\mathrm{pH}$ and oxidation state-dependent sorption behavior is driven by the mineralogical characteristics of the ore deposits, the techniques of gold mining in the Carlin Trend, and the regulatory and industry requirements for mine closure.

The Carlin Trend is generally composed of formations of silicified sedimentary rocks containing a large percentage of carbonate, siltstone, chert, and shale. The ore-zone mineralogy of Carlin Trend deposits is characterized by disseminated gold with quartz, dolomite, calcite, sericite, pyrite, marcasite, orpiment, realgar, kaolinite, illite/smectite and barite, limonite, goethite, and hematite. The altered zones are primarily products of weathered, reduced ores and are characterized by the oxidation products of the primary ore minerals and generally contain less than one percent sulfides (Shevenell et al., 1999; Tempel et al., 2000).

All of the gold ore types found in Nevada and Utah that are generally classified in the Carlin Trend are characterized by As mineralogy (Dickson et al., 1979; Singer, 1996; Shevenell et al., 1999). Arsenic is so prevalent in these ore bodies that it is a recommended indicator for new gold deposit exploration efforts (Rytuba,1985). Arsenic occurs in Carlin Trend ore bodies

Abbreviations: DDW, deionized-distilled water; LOI, loss on ignition; NBMG, Nevada Bureau of Mines and Geology; XRD, X-ray diffraction; XRF, X-ray fluorescence. 
primarily as complexes in sulfide and oxide minerals. The most common of the sulfide mineral hosts is arsenopyrite (FeAsS), and As also commonly occurs as a contaminant in pyrite $\left(\mathrm{Fe} \mathrm{As}_{x} \mathrm{~S}_{2-x}\right)$. Arsenic also occurs in other sulfides such as orpiment $\left(\mathrm{As}_{2} \mathrm{~S}_{3}\right)$, realgar $\left(\beta-\mathrm{As}_{2} \mathrm{~S}_{2}\right)$, and perhaps as a coprecipitate with jarosite in heap-leach pads $\left[(\mathrm{K}, \mathrm{As}, \mathrm{Fe})\left(\mathrm{SO}_{4}\right)_{2}(\mathrm{OH})_{6}\right]$. Arsenic might also occur in oxidized zones as arsenolite/claudetite $\left(\mathrm{As}_{2} \mathrm{O}_{3}\right)$.

The industrial process of mining a gold-ore heap, coupled with the presence of sulfide mineralogy, results in the potential for large swings in $\mathrm{pH}$ and redox potential within the heap. The aqueous chemistry of As is characterized by redox processes over a wide range in $\mathrm{pH}$ and a narrow redox potential range (Nordstrom and Archer, 2003). As a result, oxidation changes can readily occur in a heap either during mining operations or during postclosure natural hydrologic cycling of water through the heap. The redox sensitivity of As is important because the sorption characteristics, and therefore the transport behavior, of As depend on the oxidation state (e.g., Goldberg, 2002). Therefore, any efforts to estimate As flux from gold-ore heaps must include the redox chemistry and the pH-dependent sorption characteristics of both $\mathrm{As}(\mathrm{V})$ and $\mathrm{As}(\mathrm{III})$.

While cyanidation is intended to target the mineralized gold in the heap-leach pad ore, other metals and metalloids (e.g., As) are released during the leaching process by either dissolution or by complexation with cyanide (Flynn and McGill-Haslem, 1995). These other aqueous metal and metalloid species are not removed from the pregnant liquor in the mill circuit and are returned to the top of the heap with the recirculated, reclaimed cyanide leaching fluid. Thus, with time and successive cycles through the mill circuit, the concentration of these constituents can rise from trace to milligram per liter concentration levels in the heap leachate during the course of the mine life of a heap-leach pad. These byproducts of cyanide leaching of gold are the primary concern in effective environmental closure of a heap-leach facility.

Typically, concentration requirements for chemical constituents at closure are met by rinsing the heap with fresh water until the required concentrations of the constituents of concern are obtained in the heap discharge fluid. Such rinsing requires very large volumes of fresh water, an extremely valuable commodity in arid $\mathrm{Ne}$ vada. Furthermore, the rinsing process can alter the chemistry and mineralogy of the heap. For example, rinsing with fresh water can remove readily available alkalinity from the heap, leaving the residual rock pile in a geochemical condition that is conducive to sulfide oxidation and acidification. Ongoing engineering efforts to design and implement effective closure strategies for these facilities are driven by the concerns over water quality and quantity associated with heap-facility draindown and uncertainty associated with the long-term meteorologically mediated chemical flux through the heap. The development of the capability to estimate the longterm As mass flux from heap-leach pads would be useful in prioritizing mitigation resources and evaluating the long-term performance of closure design alternatives. A coupled, variably saturated flow and geochemical model has been developed to simulate As transport (Decker et al., 2006). A key component of this model is the $\mathrm{pH}$ dependent sorption of As compounds reported here.

There are numerous studies of As $\mathrm{pH}$-dependent sorption behavior onto geomedia that are potentially applicable to a complex metal ore. Studies that have examined As sorption onto agricultural soils observed that the $\mathrm{pH}$ dependence observed for both As(III) and As(V) was similar to behavior reported for sorption onto pure ferric oxide (Manning and Goldberg, 1997a) and was comparable to sorption behavior onto pure-phase clay minerals identified in the bulk soil medium (Goldberg and Glaubig, 1988). Industrially contaminated soils with high levels of As have been described through a process of identifying the dominant sorbent minerals and applying pure-phase mineral surface complexation model parameters to estimate As mobility (Lumsdon et al., 2001). There have been numerous studies conducted on a wide range of purephase minerals, including clays, metal oxides, calcite, and iron sulfides. A few of these studies are applicable to the present effort through the identification of specific primary and secondary mineral phases. Studies of As sorption onto clay minerals (Manning and Goldberg, 1996a, 1997b; Cornu et al., 2003) and onto metal oxides (Manning and Goldberg, 1996b; Manning et al., 1998; Goldberg and Johnston, 2001) are potentially applicable to a metals-bearing heap-leach facility and provide a basis for comparison to sorption behavior onto bulk soil or rock. Additional work to examine competitive sorption on pure-phase minerals is also of interest as a consequence of complex interstitial fluid geochemistry (e.g., Goldberg, 2002). There have been a large number of studies using the iron oxide and oxyhydroxide mineral family that describe pH-dependent sorption behavior (e.g., Pierce and Moore, 1982; Dzombak and Morel, 1990; Bowell, 1994; Bowell et al., 1994; Jain et al., 1999). These studies describe significant $\mathrm{pH}$-dependent sorption behavior between As (III) and As(V). Pyrite, arsenopyrite, and arsenian pyrite are all As-bearing iron-sulfide minerals that have been observed in Carlin Trend heap-leach facilities. Arsenite sorption onto pyrite and troilite (FeS) occurs in a manner analogous to sorption onto ferric oxide, but with a much sharper sorption edge at near-neutral $\mathrm{pH}$ (Bostick and Fendorf, 2003). Arsenic has been observed to coprecipitate with carbonate minerals in hydrothermal springs, resulting in the sequestration of As in these systems, a process that is not describable through surface complexation modeling or isotherm relationships (Le Guern et al., 2003), while arsenate sorption onto soil carbonates has been inferred from studies on an agricultural soil (Goldberg and Glaubig, 1988).

Applying these studies to the Carlin Trend heap-leach rock is problematic. The rock is not monomineralic and includes a specific and unusual mineral assemblage. To apply the literature directly would require identifying individual sorbent mineral species, quantifying their relative abundances, and selecting internally consistent thermodynamic and sorption parameters from the literature for the aqueous species of interest. Furthermore, for those mineral species that are present in the Carlin Trend rocks, 
but that are not reported in the As sorption literature, spectroscopic studies of these minerals with As would be needed to quantify sorption behavior for these specific minerals. One would also have to consider the possible range of mineral compositional heterogeneity at several spatial scales to establish a comprehensive set of possible models for field-scale heap-leach facilities. As an alternative, a series of whole-rock As sorption experiments encompassing the range in $\mathrm{pH}$ expected in a goldore heap-leach pad for both $\mathrm{As}(\mathrm{III})$ and $\mathrm{As}(\mathrm{V})$ was undertaken. This experimental dataset was then used to provide a basis for the development of a mathematical description of As sorption on the bulk geomedia.

\section{MATERIALS AND METHODS}

The rock samples obtained for this study were provided by two separate mining operations on the Carlin Trend, one within the Humboldt hydrographic basin in northeastern Nevada and a second from a mine in western Utah. Samples of heap material were obtained with an excavator by the mine operators from the near-surface of heaps that had been leached and subsequently rinsed. The specific locations as well as the leach and rinse history of these samples were not provided due to proprietary restrictions. These samples were assigned identification numbers CT-1 and CT-2.

In an effort to obtain a representative sample from the sample drums from each location, a 9-kg sample was removed and oven dried at $105^{\circ} \mathrm{C}$ for $48 \mathrm{~h}$. Using a jaw-crusher, both samples were then reduced to grains smaller than $1 \mathrm{~cm}$. Each sample was then split with a soils sample splitter and one of these splits was pulverized with a tungsten-carbide ball mill, and dry-sieved through a $100-\mu \mathrm{m}$ screen. Rock smaller than $100-\mu \mathrm{m}$ was used for all sorption experiments and whole-rock analyses. The process of rock drying, grinding, and sieving has been used in previous metal sorption research (Um and Papelis, 2003, 2004). A significant assumption inherent in this approach is that the mineralogical composition of the study samples did not change in the course of sample collection, preparation, and experimentation and that the gross sorption behavior should be unaffected by these activities.

The physical and geochemical properties of ground samples CT-1 and CT-2 were determined with a variety of analytical techniques. The Nevada Bureau of Mines and Geology (NBMG) analytical geochemistry laboratory analyzed heap samples CT-1 and CT-2 for bulk mineralogy using X-ray diffraction (XRD). Both CT-1 and CT-2 contain calcite and quartz, with trace amounts of kaolinite and muscovite, and minor amounts of alunite. The bulk mineralogy is consistent with the mineralogical character of the Carlin Trend deposits (Rytuba, 1985; Tooker, 1985; Shevenell et al., 1999). The presence of the minor and trace minerals is significant because these clay-mica minerals could serve as sorption surfaces (Manning and Goldberg, 1996a). In addition, the $\mathrm{Al}$ and $\mathrm{Fe}$ in these minerals could form Al- or Fe-oxides through the dissolution and subsequent hydrolysis reactions of these minerals (Charlet and Manceau, 1994). The XRD technique is sensitive to crystalline minerals in part-per-hundred relative mass quantities. As a result, many of the ore mineral phases that exist at low concentration, or in amorphous or poorly crystalline phases, are not identifiable with XRD.

Heap samples CT-1 and CT-2 were analyzed for the major elements using X-ray fluorescence (XRF) by the NBMG. The results are shown in Table 1 as the corresponding metal oxides. Silicon is the largest elemental component in both samples.
The large amount of calcium is consistent with the high percentage of carbonates expected in a Carlin Trend ore-body rock. Additionally, $\mathrm{Al}$ and $\mathrm{Fe}$ are a significant mass percentage of both rock samples. The presence of relatively large mass percentages of $\mathrm{Al}$ and $\mathrm{Fe}$ are important because oxides of these elements are known to be effective sorbent minerals for oxyanions (Arai and Sparks, 2002; Goldberg, 2002). Since both rock samples were taken near the surface of each spent heapleach pad, both samples should be significantly oxidized. This supposition is further supported by the relatively low mass percentage of total $\mathrm{S}$, reported as $\mathrm{SO}_{4}^{2-}$, given in Table 1, suggesting a low percentage of pyrite or other sulfide-bearing mineral species. Both of the samples were obtained from carbonate-hosted, sulfide-bearing, hard-rock ore bodies. As a consequence, the total mass fraction of organic $\mathrm{C}$ in the reported loss on ignition (LOI) mass percentages for both samples is likely to be below the detection level. The reported LOI for $\mathrm{CT}-1$ is $18.3 \%$, and the reported $\mathrm{CaO}$ is $19.5 \%$, while the LOI for CT- 2 is $4.67 \%$, and the $\mathrm{CaO}$ is $2.5 \%$ The XRD results indicate a significant fraction of calcite in CT-1, and the LOI mass fraction is likely to be nearly entirely composed of $\mathrm{CO}_{2}$ originating from the thermal decomposition of calcite during the XRF ignition process. Similarly, although CT-2 is not dominated by carbonate mineralogy, it is likely that the comparatively smaller LOI mass percentage is also primarily due to inorganic $\mathrm{C}$ loss.

The results of the complete whole-rock digestion, using hydrofluoric acid (HF) and inductively coupled plasma mass spectrometry analysis, are given in Table 2 . The relatively large concentration of As in both samples is consistent with the prevalence of As mineralogy in Carlin Trend ore deposits. Both rock samples were obtained from heap-leach pads that had been extensively leached. Evidence of extensive cyanide leaching is suggested by the low gold concentrations remaining in both samples (Table 2).

Sorption experiments were conducted with similar techniques used by Um and Papelis $(2003,2004)$, using batch reactors consisting of $15-\mathrm{mL}$ polystyrene centrifuge tubes. The total fluid volume of each batch reaction experiment was $10 \mathrm{~mL}$. This resulted in an approximately $5-\mathrm{mL}$ head space to assist in mixing. Mixing was accomplished with Labquake

Table 1. Major elemental composition from X-ray fluorescence and $\mathrm{SO}_{4}^{-2}$ analysis. $\dagger$

\begin{tabular}{|c|c|c|}
\hline \multirow[b]{2}{*}{ Component } & \multicolumn{2}{|c|}{$\begin{array}{l}\text { Amount of major elements, } \\
\text { as metal oxides }\end{array}$} \\
\hline & CT-1 & CT-2 \\
\hline & & \\
\hline $\mathrm{SiO}_{2}$ & 49.0 & 80.9 \\
\hline $\mathrm{TiO}_{2}$ & $\mathbf{0 . 3 8}$ & $\mathbf{0 . 3 0}$ \\
\hline $\mathbf{A l}_{2} \boldsymbol{O}_{3}$ & 7.64 & 6.01 \\
\hline $\mathrm{Fe}_{2} \mathrm{O}_{3}$ & 2.58 & 2.50 \\
\hline MnO & 0.05 & 0.03 \\
\hline MgO & 0.74 & 0.67 \\
\hline $\mathrm{CaO}$ & 19.5 & 2.50 \\
\hline $\mathrm{Na}_{2} \mathrm{O}$ & $<0.01$ & $<\mathbf{0 . 0 1}$ \\
\hline $\mathbf{K}_{2} \mathbf{O}$ & 1.34 & 1.07 \\
\hline $\mathbf{P}_{2} \mathbf{O}_{5}$ & 0.16 & 0.31 \\
\hline $\mathbf{S O}_{4}^{-2}$ & $\mathbf{0 . 3 0}$ & 0.21 \\
\hline LOI & 18.3 & 4.67 \\
\hline Total & 99.69 & 98.96 \\
\hline
\end{tabular}

$\dagger$ Sulfate analysis conducted by the Nevada Bureau of Mines and Geology with the method given in Furman (1938, p. 906-911).

$\ddagger$ LOI, loss on ignition, representing loss of volatile substances such as $\mathrm{H}_{2} \mathrm{O}$, $\mathrm{CO}_{2}$, organic $\mathrm{C}, \mathrm{Hg}$, Se, graphite (Baedecker, 1987). However, the geologic origin and the significant amount of calcite determined from X-ray diffraction analysis for both samples preclude the possibility of a significant mass fraction of organic $\mathrm{C}$ in either sample. The total calculation includes $\mathrm{SO}_{4}^{-2}$ as a component of LOI, and not as a separate component. 
Table 2. Minor elemental composition as determined from wholerock digestion and inductively coupled plasma mass spectrometry analysis.

\begin{tabular}{|c|c|c|}
\hline \multirow[b]{2}{*}{ Component } & \multicolumn{2}{|c|}{ Mass of element } \\
\hline & CT-1 & CT-2 \\
\hline & \multicolumn{2}{|c|}{$\smile \mathrm{mg} \mathrm{kg}^{-1}$} \\
\hline $\mathbf{A g}$ & 0.294 & 0.778 \\
\hline As & 865 & 336 \\
\hline As inferred from desorption experiments & 55.57 & 49.82 \\
\hline Au & $\mathbf{0 . 2 3 9}$ & 0.208 \\
\hline $\mathbf{B a}$ & 1200 & 1740 \\
\hline $\mathbf{B e}$ & 2.82 & 1.33 \\
\hline $\mathbf{B i}$ & $<\mathbf{0 . 0 0 1}$ & 0.002 \\
\hline Cd & 0.38 & 4.64 \\
\hline Co & 8.14 & $\mathbf{7 . 0 7}$ \\
\hline $\mathbf{C r}$ & 59.7 & 66.6 \\
\hline $\mathbf{C u}$ & 4.18 & 41.5 \\
\hline Mo & 4.61 & 15.3 \\
\hline $\mathbf{N i}$ & 34.1 & 48.7 \\
\hline $\mathbf{P b}$ & 43.1 & 50.7 \\
\hline Sb & 59.7 & 214 \\
\hline Se & 1.13 & 8.74 \\
\hline Sr & 584 & 219 \\
\hline Th & 2.91 & 7.71 \\
\hline $\mathbf{U}$ & 3.87 & 9.34 \\
\hline $\mathbf{V}$ & 34.5 & 579 \\
\hline $\mathbf{Z n}$ & 45.9 & 316 \\
\hline Total mass, \% & 0.30 & 0.37 \\
\hline
\end{tabular}

(Barnstead/Thermolyne, Dubuque, IA) rotating mixers using end-over-end rotation. Deionized-distilled water (DDW) was used for all solutions. The solution volume was assembled using the necessary solutions to obtain the desired As concentration, ionic strength, and $\mathrm{pH}$. Arsenic solutions were made using crystalline $\mathrm{NaAsO}_{2}$ for $\mathrm{As}(\mathrm{III})$ and crystalline $\mathrm{Na}_{2} \mathrm{HAsO}_{4} \cdot 7 \mathrm{H}_{2} \mathrm{O}$ for As(V). Ionic strength was adjusted to $0.01 M$ using $1 \mathrm{M} \mathrm{NaCl}$ solution. The final $\mathrm{pH}$ of the reactor solution was adjusted using either $0.1 M \mathrm{NaOH}$ or $0.1 M \mathrm{HCl}$. The solid concentration was $1.0 \mathrm{~g} \mathrm{~L}^{-1}$.

The solution $\mathrm{pH}$ was determined as a function of acid or base addition for both heap materials by performing 24-h leach experiments with a range of concentrations of acid and base. These results were used to determine the required volumes of acid/base to obtain a desired $\mathrm{pH}$ for both heap materials. Additional precursor experiments were conducted to determine that a 24-h sorption reaction time was needed to reach an approximate equilibrium.

Arsenate was found to be initially present in both rock samples, and this led to a significant effort to remove the arsenate mass before conducting As(III) batch sorption experiments. Several attempts were made at reducing the As(V) to As(III) in situ with little to no success. A problem with this approach is that while the reduction of $\mathrm{As}(\mathrm{V})$ is desired, additional reactions with either the As or the rock must not occur. Ultimately, the method chosen was to sequentially extract the $\mathrm{As}(\mathrm{V})$ by desorption at high $\mathrm{pH}$. This was accomplished by weighing solid into the reactor tubes in the usual manner, except that the solution was adjusted to $\mathrm{pH} 10$ to promote $\mathrm{As}(\mathrm{V})$ desorption. These reactors were equilibrated for $8 \mathrm{~h}$, centrifuged for $30 \mathrm{~min}$ at 1580 relative centrifugal force, and the supernatant extracted via a vacuum pipetter. Fresh $\mathrm{pH} 10$ solution was then added to the reactors, and the entire process repeated. The entire extraction process was repeated a total of four times. While the multistep extraction process described does not completely remove the preexisting $\mathrm{As}(\mathrm{V})$, the relatively low $\mathrm{As}(\mathrm{V})$ concentrations compared with the As(III) concentrations used in the isotherm development experiments were assumed to not affect the isotherm experiment results significantly.

The As(V) extraction methodology is justified on the basis that the geochemical conditions of the reactors are consistent with operational conditions of the heap-leach facility. During heap-leach mining, the mine operator must maintain the $\mathrm{NaCN}$ leachate solution between $\mathrm{pH} 10.5$ and 12 to prevent the following reaction from occurring (Bartlett, 1992):

$$
\mathrm{NaCN}_{(\mathrm{aq})}+\mathrm{H}_{2} \mathrm{O} \rightarrow \mathrm{HCN}_{(\mathrm{g})}+\mathrm{Na}^{+}+\mathrm{OH}^{-}
$$

Preventing this reaction from occurring is important to ensure the safety and economic viability of the operation by reducing the losses of cyanide to the atmosphere. Therefore, during the mining phase for a heap-leach facility, leachate fluid is applied in excess of $\mathrm{pH} 10.5$ for an extended period of time, typically several years. Therefore, the rock on a heap-leach facility is exposed to a significantly more aggressive treatment than what was done in the laboratory in preparation for the As(III) sorption experiments. In conclusion, the pretreatment methodology to remove $\mathrm{As}(\mathrm{V})$ from the rock is consistent with the prior geochemical history of the rock samples, and it is very unlikely that any additional $\mathrm{Fe}$ or $\mathrm{Al}$ mineral dissolution or precipitation reactions occurred in the laboratory that had not already occurred during the several years that the rock was mined.

A hydride-generation atomic absorption spectrometry method was used to speciate and analyze the sorption experiment eluent samples (Manning and Martens, 1997). The carrier eluent used was $25 \mathrm{~m} M \mathrm{NaOH}$ and $1 \%(\mathrm{v} / \mathrm{v}) \mathrm{MeOH}$ in de-aired DDW. The reductant solution used in the hydride generation process was $3 \mathrm{~g}$ of $\mathrm{NaBH}_{4}$ dissolved into $500 \mathrm{~mL}$ of de-aired DDW with $2.5 \mathrm{~g}$ of $\mathrm{NaOH}$. The acid solution used in the hydride generator was $6 \mathrm{M} \mathrm{HCl}$ using ACS plus reagent-grade acid. Carrier eluent and hydride generator solutions were made fresh before each analysis. All de-aired DDW was prepared by stirring under vacuum for $24 \mathrm{~h}$.

Calibration standards were made before each analysis with the same solid-phase chemicals used to make solutions. Check standards were made using chemicals from a second chemical supplier. The calibration standards were made by diluting with DDW water at the same ionic strength as the experiment.

The method reported by Manning and Martens (1997) was adapted for use with a computer controlled Varian 8050 (Varian, Palo Alto, CA) spectrophotometer with an electric furnace and continuous hydride generation. The adaptations to the method were limited to the manipulation of the software that controls the operation of the spectrophotometer detector to enable continuous data collection during sample speciation.

\section{RESULTS AND DISCUSSION}

Both $\mathrm{As}(\mathrm{V})$ and As(III) on CT-1 and CT-2 exhibited strong $\mathrm{pH}$-dependent sorption behavior. The $\mathrm{As}(\mathrm{V})$ concentrations used for both CT-1 and CT-2 were $100 \mu \mathrm{g}$ $\mathrm{L}^{-1}\left(10^{-5.87} M\right), 200 \mu \mathrm{g} \mathrm{L}^{-1}\left(10^{-5.57} M\right), 500 \mu \mathrm{g} \mathrm{L}^{-1}$ $\left(10^{-5.18} M\right)$, and $1000 \mu \mathrm{g} \mathrm{L}^{-1}\left(10^{-4.87} M\right)$ as As(V). An additional concentration of $2000 \mu \mathrm{g} \mathrm{L}^{-1}\left(10^{-4.57} M\right)$ was used with CT-2. The results for the As(V) experiments are shown in Fig. 1 and 2.

The As(III) concentrations used for both CT-1 and CT-2 were 100,500 , and $1000 \mu \mathrm{g} \mathrm{L}^{-1}$, with an additional concentration of $3500 \mu \mathrm{g} \mathrm{L}^{-1}\left(10^{-4.33} \mathrm{M}\right)$ for CT-1 (Fig. 3 and 4). Because both CT-1 and CT-2 had an initial sorbed mass of $\mathrm{As}(\mathrm{V})$ and because of the possibility of As(III) oxidation during the experiment, $\mathrm{As}(\mathrm{V})$ concentrations were determined for these experiments in addition to As(III). Detectable amounts of $\mathrm{As}(\mathrm{V})$ were observed in the As(III) sorption experiments for both CT-1 and CT-2 in the $100 \mu \mathrm{g} \mathrm{L}^{-1}$ and $500 \mu \mathrm{g} \mathrm{L}^{-1} \mathrm{As}$ (III) 


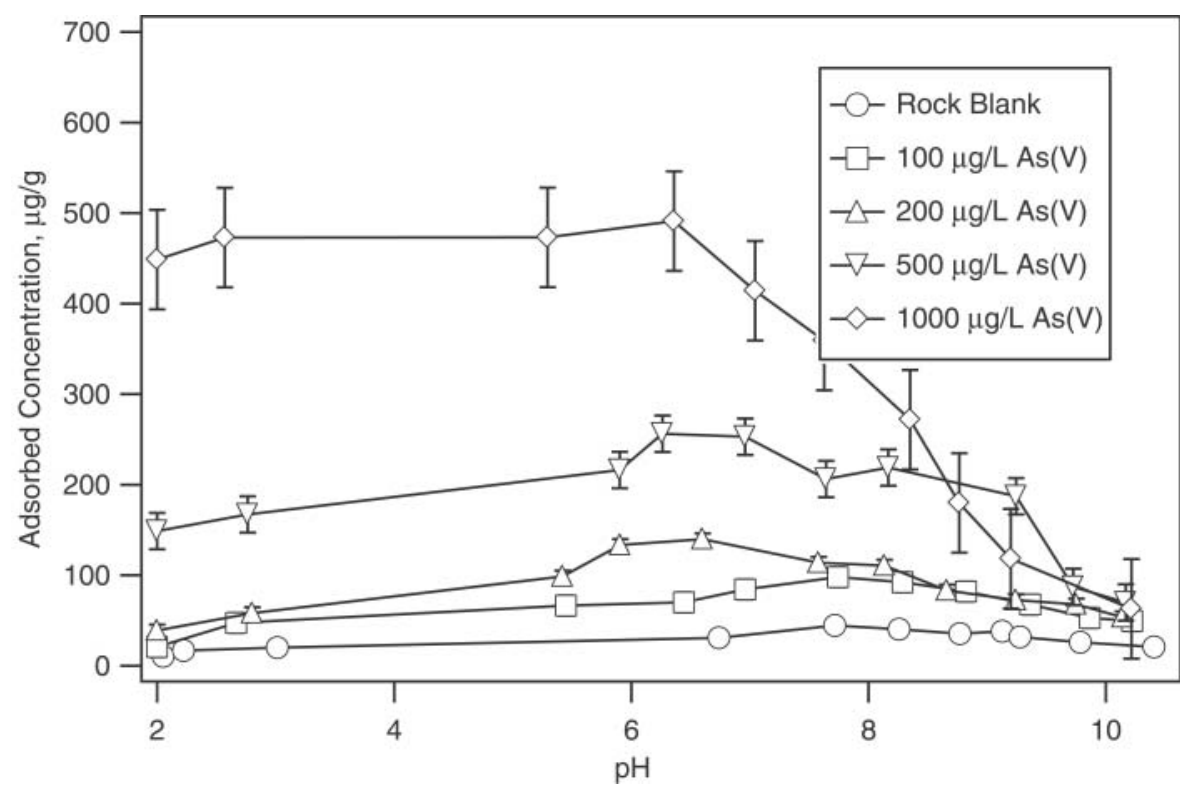

Fig. 1. Arsenate sorption data for heap material CT-1. Error bars are inclusive of analytical and experimental error.

experiments, and in the $3500 \mu \mathrm{g} \mathrm{L} \mathrm{L}^{-1} \mathrm{As}(\mathrm{III}) \mathrm{CT}-1$ experiment. The average $\mathrm{As}(\mathrm{V})$ concentrations in these experiments were 20,50 , and $100 \mu \mathrm{g} \mathrm{L}{ }^{-1}$, respectively.

The $\mathrm{As}(\mathrm{V})$ results for both CT-1 and CT-2 were generally consistent with $\mathrm{As}(\mathrm{V})$ sorption onto iron oxyhydroxide and agricultural soils as reported in previous studies (Dzombak and Morel, 1990; Manning and Goldberg, 1996a, 1997a). In particular, the decrease in apparent sorption concentration with increasing $\mathrm{pH}$ is consistent with results reported in the literature. The shape of the sorption envelopes for $\mathrm{As}(\mathrm{V})$ are similar to that reported for amorphous aluminum and iron oxide (Fig. 1 and 2) (Dzombak and Morel, 1990; Goldberg, 2002).

The As(III) results are also generally consistent with the published literature dealing with sorption onto soils and minerals common to soils (Manning and Goldberg, 1996a, 1997a; Manning et al., 1998; Goldberg, 2002). The smaller degree of $\mathrm{pH}$ dependence and the opposite $\mathrm{pH}$-dependent behavior as compared with the As(V) data are also comparable to the observations reported in these previous studies.

A critical assumption built into sorption isotherms is that the oxidation state of the aqueous species is the same as that of the adsorbed species. If the sorption mechanism is an inner-sphere complexation reaction that proceeds relatively rapidly, then this assumption is reasonable. Alternatively, it is possible that a heterogeneous mixture of sorbed As(III) and As(V) anionic complexes could be represented on the mineral surface as a result of redox reactions at the mineral surface. Previous studies with anions have suggested a relationship between acid-base pair chemistry and oxyanion complex binding

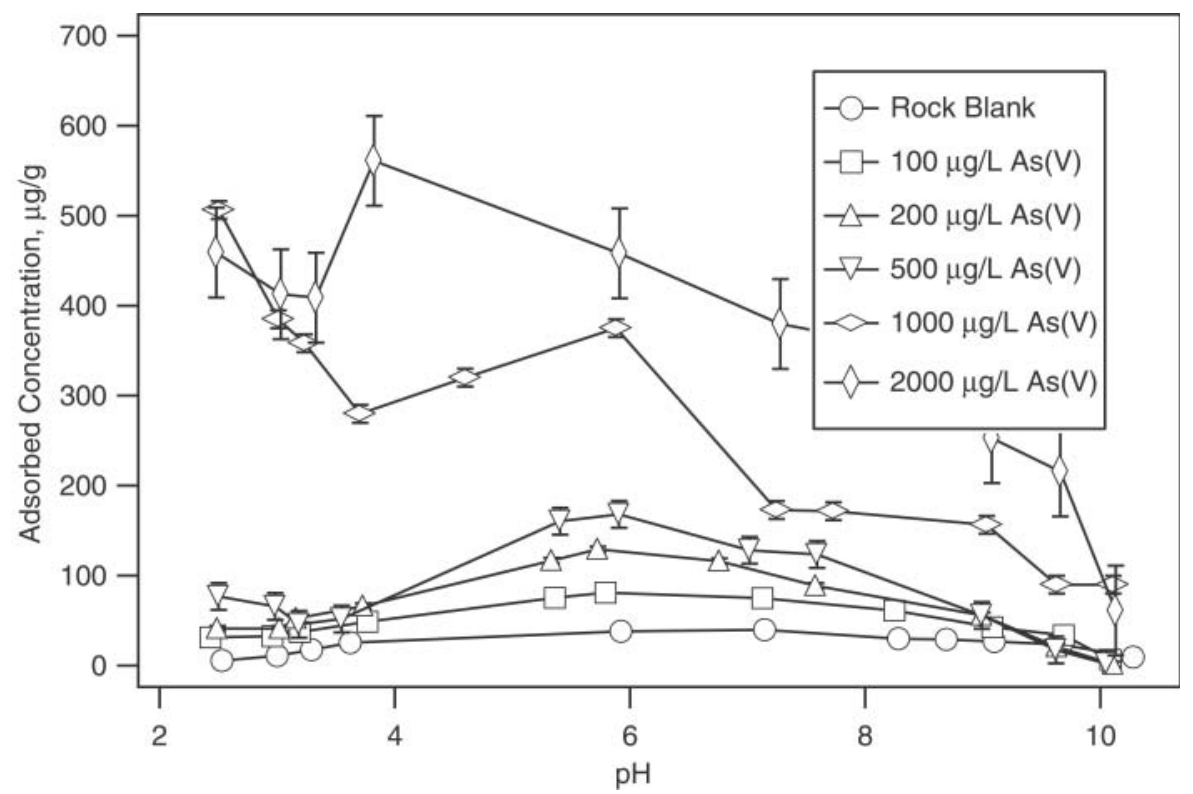

Fig. 2. Arsenate sorption data for heap material CT-2. Error bars are inclusive of analytical and experimental error. 


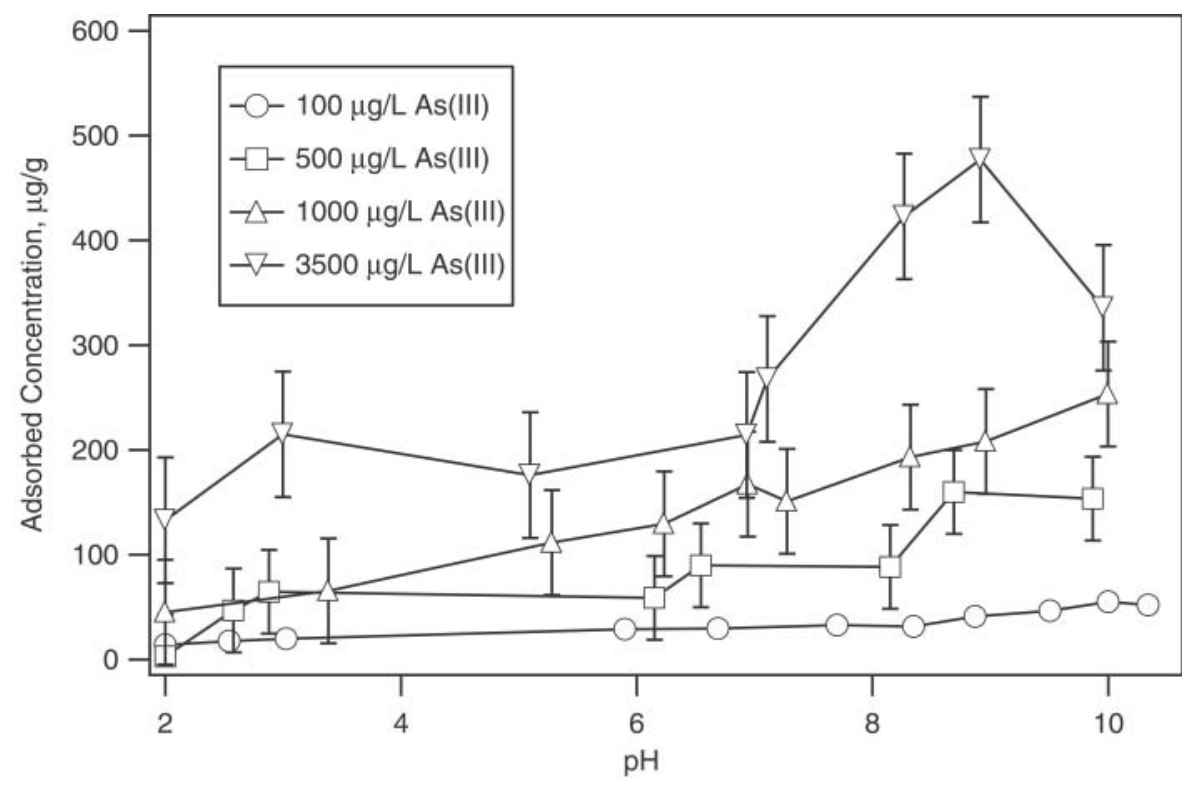

Fig. 3. Arsenite sorption data for heap material CT-1. Error bars are inclusive of analytical and experimental error.

strength (Hingston et al., 1967, 1972; Stumm et al., 1980; Stumm, 1992). Differences in acid-base chemistry of the two As oxidation states, therefore, would be expected to result in differences in the sorption affinity of arsenate and arsenite oxyanions. There is some evidence that a nonhomogeneous distribution of As oxyanions may be present on the mineral surfaces of both rock samples. The relatively larger mass of As released from the hydrofluoric acid digestions as compared with the adsorbed As mass calculated from the As desorption experiments (Table 2) suggests that a significant amount of the As mass initially bound to the rock is not released by the experimental techniques used to conduct the sorption work. The possibility of As-bearing mineral phases contributing to the digested As mass cannot be ignored, but is discounted by the lack of XRD evidence of these minerals and the extensive cyanide leaching of both of these samples. It is also possible that although both rock sorbent samples were ground smaller than $100 \mu \mathrm{m}$, the whole-rock digest analyses released sorbed As that remained unavailable during the surface-controlled desorption experiments. Additional micromineralogy and surface spectroscopy would provide the data necessary for a conclusive analysis.

The possibility of a heterogeneous distribution of sorbate-sorbent bond energies necessarily implies the possibility of a distribution of As(III) and As(V) oxyanion species on the sorbent surface, even while attempts were made to ensure a homogeneous sorbate solution. Therefore, the sorption data presented may well reflect contributions from both oxidation states. However, there are no clear trends in the sorption data that would

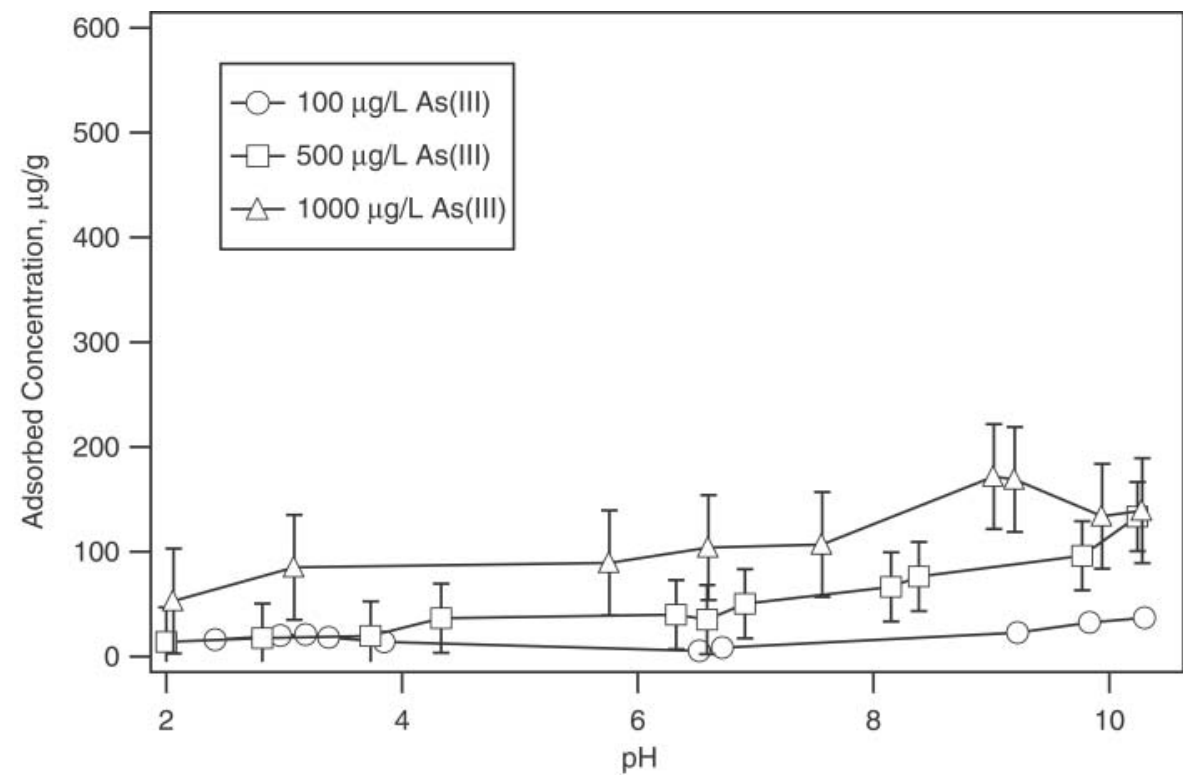

Fig. 4. Arsenite sorption data for heap material CT-2. Error bars are inclusive of analytical and experimental error. 
Table 3. Keren-type pH-dependent isotherm model parameters. Units for the calculated isotherm surface plot are: $C_{\mathrm{e}}, \mu \mathrm{g} \mathrm{L}^{-1} ; q_{\mathrm{e}}, \mu \mathrm{g} \mathrm{g} \mathrm{g}^{-1}$; $\mathbf{p H}=-\log \left[\mathbf{H}^{+}\right]$.

\begin{tabular}{|c|c|c|c|c|}
\hline \multirow[b]{2}{*}{ Parameter } & \multicolumn{2}{|c|}{ CT-1 } & \multicolumn{2}{|c|}{ CT-2 } \\
\hline & $\operatorname{As}(V)$ & $\operatorname{As}($ III) & $\operatorname{As}(\mathbf{V})$ & As(III) \\
\hline $\boldsymbol{A}$ & 0.0007962 & 0.0002831 & 0.0003601 & 0.0006856 \\
\hline $\boldsymbol{B}$ & 46.99 & 6297 & 22.66 & 984.8 \\
\hline$C$ & 548600 & 3526000 & 379600 & 169500 \\
\hline$D$ & 0.1250 & 1.003 & 1.297 & 32.49 \\
\hline$q_{\mathrm{m}}, \mu \mathrm{g} \mathrm{g}_{\text {rock }}^{-1}$ & 1200 & 377 & 1188 & 201 \\
\hline$r^{2}$ & 0.82 & 0.91 & 0.80 & 0.81 \\
\hline RMSE & 62 & 26 & 74 & 24 \\
\hline F statistic & 1.17 & 0.98 & 1.16 & 1.22 \\
\hline F critical, $\alpha$ & $1.13,0.35$ & $0.55,0.05$ & $1.14,0.35$ & $1.18,0.30$ \\
\hline
\end{tabular}

reflect an isotherm superposition of $\mathrm{As}(\mathrm{III})$ and $\mathrm{As}(\mathrm{V})$ behavior. The significant differences in $\mathrm{pH}$-dependent sorption behavior between $\mathrm{As}(\mathrm{III})$ and $\mathrm{As}(\mathrm{V})$ for both sorbate rock samples, coupled with similar results reported in the soils literature, generally support the conclusion that the data do not reflect a significant competitive sorption behavior.

\section{Modeling Arsenic Oxyanion Sorption}

There are several models that are commonly used to describe sorption processes at the mineral-water interface. Empirical isotherm models are the most commonly applied approach because of their ease of use and wide range of applicability in mass transport and geochemical simulation codes. Isotherm models require a qualitative knowledge of mineral composition and are dependent on the observed relationships between aqueous and adsorbed phases of the adsorbing species (Koretsky, 2000). There are limitations in the isotherm approach in numerical transport models (Bethke and Brady, 2000); however, properly applied isotherm relationships are a valid representation of water-rock sorption reactions and are the most commonly applied means of incorporating water-rock reactions into transport simulations. Surface-complexation models are widely used in mineral-water interface studies, but they are not routinely incorporated into reactive flow and transport models due to the difficulties in obtaining the necessary model parameters and unique parameter sets when inversion methodologies are applied to batch reaction sorption data. Surface-complexation models require a thorough, quantitative understanding of sorbent micromineralogy because these models depend on parameters that are mineral and mineral-ion complex specific. Therefore, to use a surface-complexation model to simulate sorption in a highly heterogeneous rock matrix such as the rock samples that are the subject of this paper would require that model parameters for individual mineral species and ions be obtained or estimated through a numericalinversion process. Further, a means of representing subsurface mineral heterogeneity must be developed to adequately simulate the geochemical complexities of the reactive rock matrix at scales that are meaningful to field-scale transport problems. Combining the uncertainty involved in surface complexation model parameter estimation from numerical inversion of experimental data with the difficulty in calculating a unique numerical solution with multiple minerals and mineral-specific estimated parameters, in a complex, variably saturated flow regime, challenges the usefulness of the surfacecomplexation approach in all but the most refined and characterized mineralogical systems. Many of these aspects of the surface-complexation approach are the subjects of ongoing research to provide a thermodynamically based representation of sorption chemistry at multiple scales of chemical and physical heterogeneity (Davis et al., 1998; Al et al., 2000; Appelo et al., 2002).

An advantage of an isotherm approach is that the isotherm is developed for a "whole-rock" sample that is inclusive of at least some significant subset of the mineral heterogeneity present in a representative volume of rock at the field scale. However, one of the tenets of the isotherm approach is that isotherms are valid only for a constant $\mathrm{pH}$ or, alternatively, that sorption is independent of $\mathrm{pH}$. Because As oxyanion sorption exhibits strong $\mathrm{pH}$ dependence, the applicability of the Freundlich or Langmuir isotherm formulations is problematic. One possible approach to using a standard isotherm to represent As oxyanion sorption is to develop a set of isotherms, each identified with a unique and constant $\mathrm{pH}$. However, the application of this approach to a flow and transport model is impractical.

A $\mathrm{pH}$-dependent formulation that was developed to describe B sorption on several mineral species and soils has the generalized form of the Langmuir equation (Keren et al., 1981a, 1981b). This formulation describes the sorption of $\mathrm{B}(\mathrm{OH})_{3}, \mathrm{~B}(\mathrm{OH})_{4}^{-}$, and $\mathrm{OH}^{-}$with the assumption that these complexes are all competing for the same sorption sites. The Keren formulation is, in part, dependent on the $\mathrm{B}$ hydrolysis reaction

$$
\mathrm{B}(\mathrm{OH})_{3}+2 \mathrm{H}_{2} \mathrm{O} \rightleftharpoons \mathrm{B}(\mathrm{OH})_{4}^{-}+\mathrm{H}_{3} \mathrm{O}^{+}
$$

The Keren $\mathrm{pH}$-dependent $\mathrm{B}$ sorption formulation is described by

$$
q_{\mathrm{e}}=q_{\mathrm{m}} \frac{k_{\mathrm{HB}} c_{\mathrm{HB}}+k_{\mathrm{B}} c_{\mathrm{B}}}{1+k_{\mathrm{HB}} c_{\mathrm{HB}}+k_{\mathrm{B}} c_{\mathrm{B}}+k_{\mathrm{OH}} c_{\mathrm{OH}}}
$$

where $q_{\mathrm{e}}$ is the metal ion (in this case $\mathrm{B}$ ) concentration sorbed on the solid phase at equilibrium $\left(\mathrm{mol} \mathrm{g}^{-1}\right) ; q_{\mathrm{m}}$ is the Langmuir monolayer saturation capacity $\left(\mathrm{mol} \mathrm{g}^{-1}\right)$; $c_{\mathrm{HB}}, c_{\mathrm{B}}$, and $c_{\mathrm{OH}}$ are the solution activities $\left(\mathrm{mol} \mathrm{L}^{-1}\right)$ of the species $\mathrm{B}(\mathrm{OH})_{3}, \mathrm{~B}(\mathrm{OH})_{4}^{-}$, and $\mathrm{OH}^{-}$; and $k_{\mathrm{HB}}, k_{\mathrm{B}}$, and $k_{\mathrm{OH}}$ are sorption coefficients related to the binding 
energies of these species (Communar et al., 2004). The relationship in Eq. [3] is reduced through the use of relationships describing total $\mathrm{B}$ concentration to concentrations of each of the two B species to obtain

$$
\begin{aligned}
q_{\mathrm{e}} & =q_{\mathrm{m}} \frac{K_{\mathrm{L}} C_{\mathrm{e}}}{1+K_{\mathrm{L}} C_{\mathrm{e}}} \\
K_{\mathrm{L}} & =\frac{\left(k_{\mathrm{HB}}+A k_{\mathrm{B}}\right)}{(1+A)\left(1+k_{\mathrm{OH}} c_{\mathrm{OH}}\right)}
\end{aligned}
$$

where $A \approx K_{\mathrm{h}}\left(10^{4} \mathrm{c}_{\mathrm{OH}}\right)$ is the coefficient dependent on the solution $\mathrm{OH}^{-}$concentration, $K_{\mathrm{h}}$ is the $\mathrm{B}$ hydrolysis constant associated with the reaction in Eq. [1] $\left(K_{\mathrm{h}}=\right.$ $5.9 \times 10^{-10}$ at $\left.298^{\circ} \mathrm{K}\right)$, and $C_{\mathrm{e}}=c_{\mathrm{HB}}+c_{\mathrm{B}}($ Communar et al., 2004).

Keren's model is successful in describing B sorption on pyrophyllite (Keren et al. 1994), montmorillonite (Keren et al. 1981a, 1981b; Keren and Gast 1983), and several soils (Mezuman and Keren, 1981; Communar et al., 2004). However, in spite of the apparent success of this approach to incorporate $\mathrm{pH}$ dependence, Keren et al. (1981a) concluded that the sorption coefficients of the individual sorbing species have no physical significance, and they are used as model-fitting parameters. Therefore, Keren's formulation, for the purposes of this paper, can be simplified to the following:

$$
\begin{gathered}
q_{\mathrm{e}}=q_{\mathrm{m}} \frac{K_{\mathrm{L}} C_{\mathrm{e}}}{1+K_{\mathrm{L}} C_{\mathrm{e}}} \\
K_{\mathrm{L}}=\frac{A+B c_{\mathrm{OH}}}{\left(1+C c_{\mathrm{OH}}\right)\left(1+D c_{\mathrm{OH}}\right)}
\end{gathered}
$$

where $A, B, C$, and $D$ are constants. The relationship for $K_{\mathrm{L}}$ in Eq. [6] can be recast in terms of $\mathrm{pH}$ as

$$
\begin{gathered}
c_{\mathrm{OH}}=10^{(\mathrm{pH}-14)} \\
K_{\mathrm{L}}=\frac{A+B \times 10^{(\mathrm{pH}-14)}}{1+C \times 10^{(\mathrm{pH}-14)}+D \times\left[10^{(\mathrm{pH}-14)}\right]^{2}}
\end{gathered}
$$

Keren's pH-dependent formulation can be applied to describing As oxyanion sorption. The aqueous hydrolysis reactions for arsenite are described by Nordstrom and Archer (2003)

$$
\begin{aligned}
& \mathrm{H}_{3} \mathrm{AsO}_{3} \rightleftharpoons \mathrm{H}_{2} \mathrm{AsO}_{3}^{-}+\mathrm{H}^{+} \quad \mathrm{pK}=9.17 \\
& \mathrm{H}_{2} \mathrm{AsO}_{3}^{-} \rightleftharpoons \mathrm{HAsO}_{3}^{2-}+\mathrm{H}^{+} \quad \mathrm{pK}=14.1 \\
& \mathrm{HAsO}_{3}^{2-} \rightleftharpoons \mathrm{AsO}_{3}^{3-}+\mathrm{H}^{+} \quad \mathrm{pK}=15
\end{aligned}
$$

where only the first deprotonation step is applicable to a heap-leach environment because of the $\mathrm{pH}$ range. The aqueous complexation reactions for arsenate are similarly described by Nordstrom and Archer (2003)

$$
\begin{aligned}
& \mathrm{H}_{3} \mathrm{AsO}_{4} \rightleftharpoons \mathrm{H}_{2} \mathrm{AsO}_{4}^{-}+\mathrm{H}^{+} \quad \mathrm{pK}=2.3 \\
& \mathrm{H}_{2} \mathrm{AsO}_{4}^{-} \rightleftharpoons \mathrm{HAsO}_{4}^{2-}+\mathrm{H}^{+} \quad \mathrm{p} K=6.99 \\
& \mathrm{HAsO}_{4}^{2-} \rightleftharpoons \mathrm{AsO}_{4}^{3-}+\mathrm{H}^{+} \quad \mathrm{p} K=11.8
\end{aligned}
$$

where only the first two reactions are applicable to a heap-leach environment. These reactions can be reduced to a single reaction (Appelo and Postma, 1993)

$$
\mathrm{H}_{3} \mathrm{AsO}_{4} \rightleftharpoons \mathrm{HAsO}_{4}^{2-}+2 \mathrm{H}^{+} \quad \mathrm{pK}=9.1
$$

Since both arsenate and arsenite hydrolysis reactions can be described by a single reaction involving two components for each oxidation state, Keren's $\mathrm{pH}$-dependent Langmuir isotherm formulation can be analogously applied to each oxidation state, assuming that the As species compete for the same sorption sites.

As an alternative to the Keren approach, a choice was made to incorporate a $\mathrm{pH}$-dependent function into the Sips (1950), or Langmuir-Freundlich, isotherm. The Sips isotherm is written as

$$
q_{\mathrm{e}}=q_{\mathrm{m}} \frac{\left(a_{\mathrm{S}} C_{\mathrm{e}}\right)^{n_{\mathrm{s}}}}{1+\left(a_{\mathrm{S}} C_{\mathrm{e}}\right)^{n_{\mathrm{S}}}}
$$

where $a_{\mathrm{S}}$ is the Sips isotherm constant, $n_{\mathrm{S}}$ is the Sips isotherm exponent, and the remaining terms are as defined above (Ho et al., 2002). In the special case where $n_{\mathrm{S}}=1$, this formulation reduces to the familiar Langmuir isotherm form.

To incorporate $\mathrm{pH}$-dependence into Eq. [12], one possible form is

$$
q_{\mathrm{e}}=q_{\mathrm{m}} k(\mathrm{pH}) \frac{\left(a_{\mathrm{S}} C_{\mathrm{e}}\right)^{n_{\mathrm{s}}}}{1+\left(a_{\mathrm{S}} C_{\mathrm{e}}\right)^{n_{\mathrm{s}}}}
$$

where $k(\mathrm{pH})$ is a function of $\mathrm{pH}$ that matches the observed $\mathrm{pH}$ dependence. This form of the Sips isotherm empirically incorporates $\mathrm{pH}$ as an additional independent variable to a standard isotherm. The function $k(\mathrm{pH})$ can take any form that is suitable. A form that is suitable for the $\mathrm{As}(\mathrm{V})$ and $\mathrm{As}(\mathrm{III})$ datasets for both CT- 1 and CT- 2 is

$$
k(\mathrm{pH})=\frac{1}{1+\delta e^{-\varepsilon \mathrm{pH}}}
$$

where $\delta$ and $\varepsilon$ are constants.

This expression encompasses two analytically measured parameters, $C_{\mathrm{e}}$ and $\mathrm{pH}$, and one calculated parameter, $q_{\mathrm{e}}$. The remaining parameters are used to fit the $\mathrm{pH}$-dependent isotherm in Eq. [13] and [14] to the observed data.

The $\mathrm{pH}$-dependent Keren formulation in Eq. [5] and [8] and the Sips isotherm formulation given in Eq. [13] and [14] were used to fit isotherms to the experimental sorption data for both $\mathrm{As}(\mathrm{V})$ and $\mathrm{As}(\mathrm{III})$ onto heap samples CT-1 and CT-2. The inversion was accomplished using an iterative, nonlinear, numerical routine in a computer spreadsheet. Several different optimization functions were examined, including the modified Marquardt approach described in Ho et al. (2002). However, the sum of the squared error produced the smallest RMSE while providing the best overall fit to the experimental data. The regression results for the Keren isotherm are given in Table 3, and that for the Sips isotherm are given in Table 4.

The $\mathrm{pH}$-dependent sorption surfaces using the Keren formulation for As(V) and As(III) onto CT-1 are shown 
Table 4. Sips-type pH-dependent isotherm model parameters. Units for the calculated isotherm surface plot are: $C_{\mathrm{e}}, \mu \mathrm{g} \mathrm{L}^{-1}$; $q_{\mathrm{e}}, \mu \mathbf{g ~ g}^{-1} ; \mathbf{p H}=-\log \left[\mathbf{H}^{+}\right]$.

\begin{tabular}{|c|c|c|c|c|}
\hline \multirow[b]{2}{*}{ Parameter } & \multicolumn{2}{|c|}{ CT-1 } & \multicolumn{2}{|c|}{ CT-2 } \\
\hline & $\operatorname{As}(V)$ & As(III) & $\operatorname{As}(\mathbf{V})$ & As(III) \\
\hline$\delta$ & 0.000004891 & 4.925 & 0.00007911 & 14.62 \\
\hline & -1.404 & 0.4211 & -1.063 & 0.2795 \\
\hline$q_{\mathrm{m}}, \mu \mathrm{g} \mathrm{g}_{\text {rock }}^{-1}$ & 960 & 337 & 1400 & 401 \\
\hline$a_{\mathrm{s}}$ & 0.001151 & 0.002011 & $\mathbf{0 . 0 0 0 3 0 0 7}$ & 0.004123 \\
\hline$n_{\mathrm{s}}$ & 1 & 1 & 1 & 1 \\
\hline$r^{2}$ & 0.81 & 0.84 & 0.82 & 0.77 \\
\hline RMSE & 63 & 35 & 71 & 27 \\
\hline$F$ statistic & 1.22 & 1.38 & 1.16 & 1.35 \\
\hline$F$ critical, $\alpha$ & $1.18,0.30$ & $1.34,0.20$ & $1.14,0.35$ & $1.30,0.20$ \\
\hline
\end{tabular}

in Fig. 5 and 6. The experimental data are shown with the fitted isotherm surfaces superimposed onto the plots of sorption data. The general shapes of the Keren formulation isotherm surfaces for CT-2 are very similar to that of CT-1 (Table 3). The Pearson's correlation coefficients ( $r^{2}$ values) for all four Keren formulation isotherms are at least 0.80 (Table 3). However, the regressions using the Keren isotherm formulation are significant at $65 \%$ for the As(V) data, $70 \%$ for the CT-2 As(III) data, and $95 \%$ for the CT-1 As(III) data. Though the regression significance is generally quite low with the exception of the CT-1 As(III) result, the Keren isotherm does capture the general behavior and the overall quantitative characteristics of the experimental data. The results for $\mathrm{As}(\mathrm{V})$ are consistent with the $\mathrm{pH}$ dependence illustrated for soils and hydrous ferric oxides, and the "s"-shaped surfaces in the As(III) isotherms are consistent with sorption onto metal oxides and clays as reported in several previous studies (e.g., Goldberg, 2002).

The $\mathrm{pH}$-dependent Sips isotherm formulation was also applied to the CT-1 and CT-2 As(V) and As(III) batch sorption data. The Sips isotherm parameters are given in Table 4, and the isotherm surfaces for CT-1 are shown in Fig. 7 and 8. The results for CT-2 are similar to that of CT-1 (Table 4). The $r^{2}$ values for the regressions using the Sips isotherm are not quite as large as those

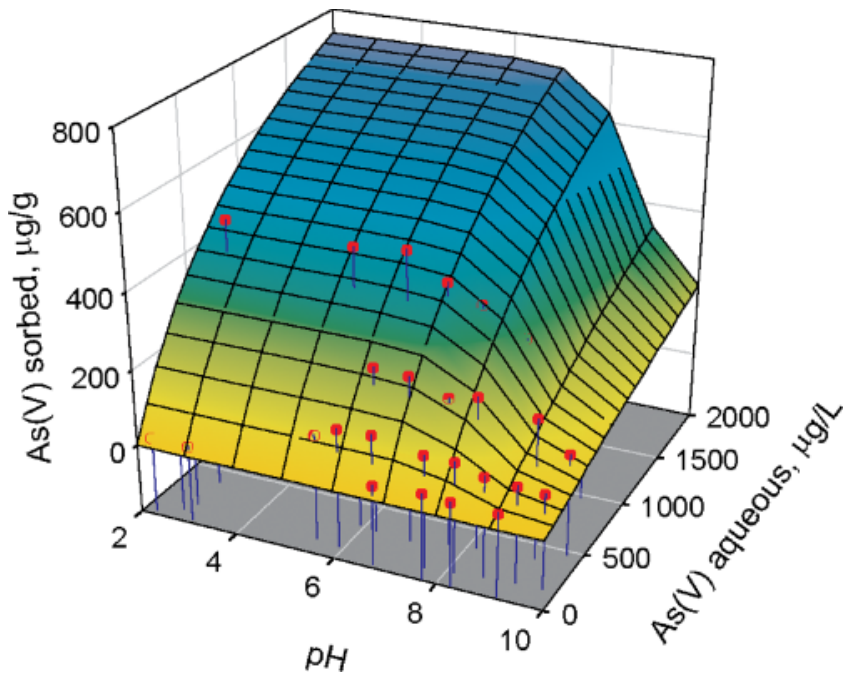

Fig. 5. CT-1 As(V) experimental sorption data with the Keren formulation isotherm surface.

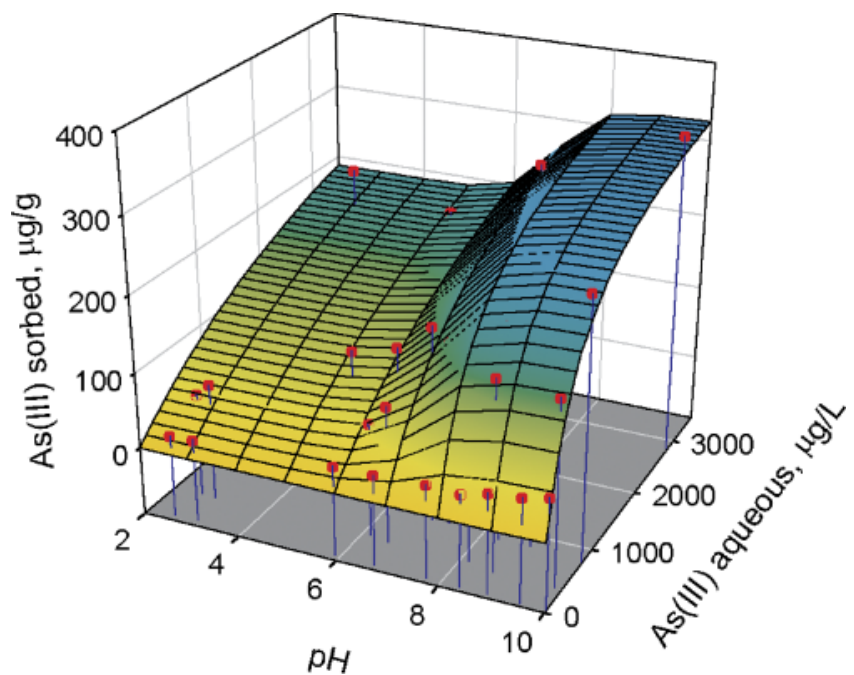

Fig. 6. CT-1 As(III) experimental sorption data with the Keren formulation isotherm surface.

using the Keren isotherm. However, the RMSE values and the regression significance statistics are quite similar (Tables 3 and 4). Therefore, the Sips isotherm does not provide an improved representation of the data. The Keren isotherm appears to be capable of producing a sharper sorption edge than the Sips isotherm. However, this difference may only be significant for some applications. Literature results for As(III) sorption onto montmorillonite and illite, for example, are characterized by a diffuse sorption envelope (e.g., Goldberg, 2002).

The differences in the model parameters for both the Keren-type (Table 3) and the Sips-type (Table 4) isotherms are not as large as might be expected given the differences in gross mineralogy and in total $\mathrm{SiO}_{2}$ (Table 1). However, the similarities in isotherm parameter sets for As(V) and As(III) between CT-1 and CT-2 are matched by nearly identical total $\mathrm{Fe}$ and $\mathrm{Al}$ mass percentages in both samples. This observation, coupled with qualitative comparisons to monomineralic studies,

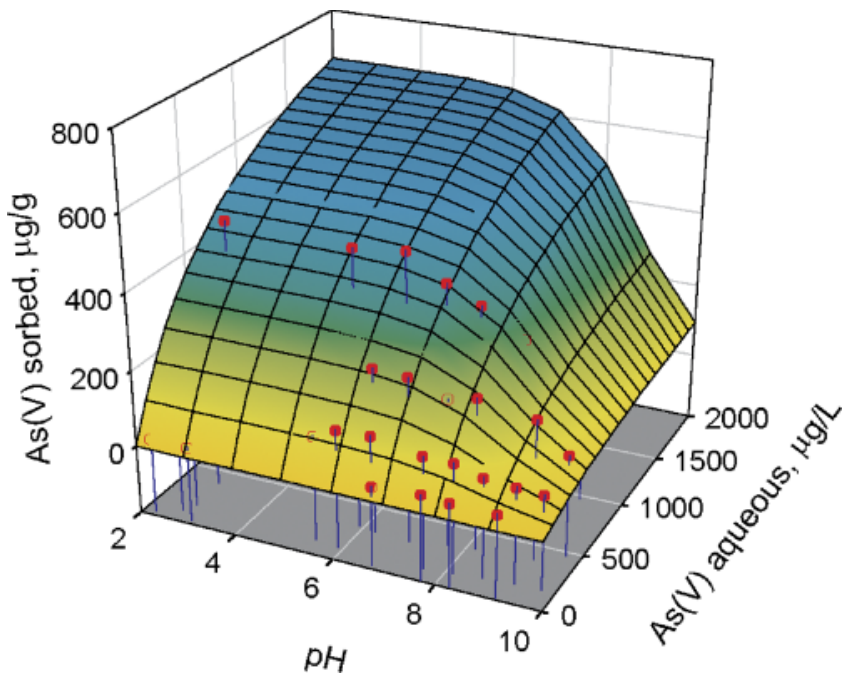

Fig. 7. CT-1 As(V) experimental sorption data with the Sips formulation isotherm surface. 


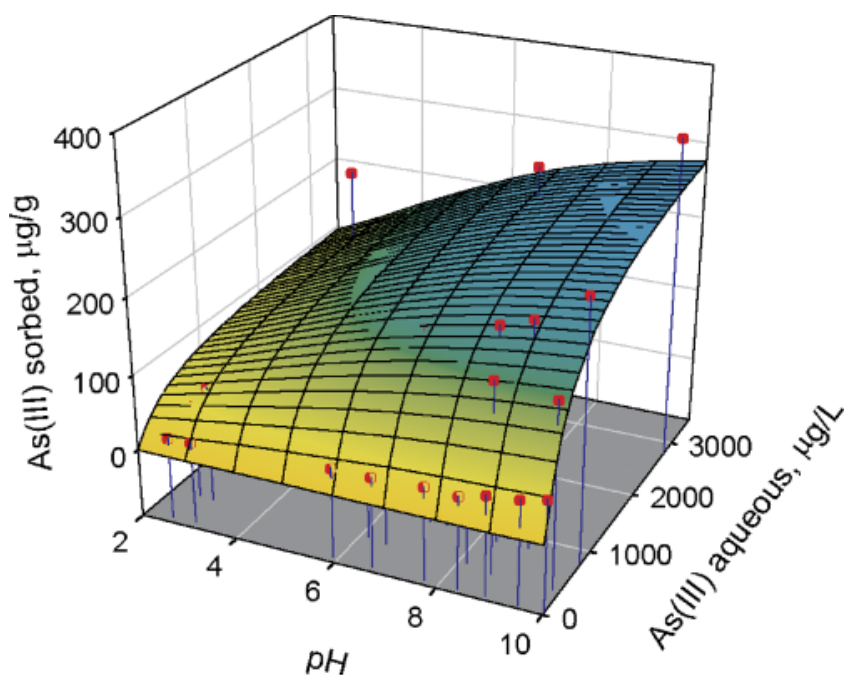

Fig. 8. CT-1 As(III) experimental sorption data with the Sips formulation isotherm surface.

provides a means to infer that As is likely sorbing onto iron and aluminum oxides. The diffuse sorption edges, and the $\mathrm{pH}$ dependence demonstrated in both $\mathrm{As}(\mathrm{V})$ and As(III) experimental datasets are consistent with earlier studies (Manning and Goldberg, 1996b; Manning et al., 1998; Goldberg and Johnston, 2001). However, the possibility of sorption onto carbonate and iron-As sulfide mineral surfaces is also probable in view of the mineralogic setting (Bostick and Fendorf, 2003; Goldberg and Glaubig, 1988).

\section{CONCLUSIONS}

The As(V) and As(III) pH-dependent sorption behavior observed on the two carbonaceous gold ore samples studied is consistent with the literature for mineralogically heterogeneous soils. The differences between CT-1 and CT-2 sorption behavior are noticeable, but are not as significant as initially expected given that these samples originated from two different mine sites that are separated by more than $100 \mathrm{~km}$. However, the similar sorption behavior between CT-1 and CT-2 is generally consistent with the comparable bulk mineralogical and whole-rock analyses of these samples. This suggests that the approach used here may be generally useful for evaluating As behavior across the Carlin Trend mines.

A simplified version of Keren's $\mathrm{pH}$-dependent isotherm formulation was chosen to describe the $\mathrm{pH}$-dependent sorption data for $\mathrm{As}(\mathrm{V})$ and $\mathrm{As}(\mathrm{III})$. In addition, a $\mathrm{pH}$ dependent function was incorporated into the Sips, or Langmuir-Freundlich, isotherm. These approaches provide empirical isotherm formulations that are $\mathrm{pH}$ dependent, and are suitable for both As(III) and As(V) sorption. The isotherm equations are closed-form expressions that are valid for any positive value of $\mathrm{pH}$ and aqueous sorbate concentration. The adsorbed concentration is only dependent on the aqueous sorbate concentration, $\mathrm{pH}$, and the remaining isotherm fitting parameters. Thus, these formulations are readily incorporated into a flow and transport model that includes $\mathrm{pH}$ as a variable. As an example, these formulations have been incorpo- rated into a variably saturated reactive transport solver to estimate As transport behavior in heap-leach facilities (Decker et al., 2006).

The advantage of the sorption isotherm approach, compared with a surface complexation approach, is that an isotherm approach describes laboratory batch reaction data that are inclusive of the whole-rock mineralogy without explicitly quantifying either the mineralogical composition or the relative abundance of these minerals. For application to full-scale heap-leach systems for which detailed mineralogical data do not exist and would be difficult, if not impossible, to obtain due to proprietary concerns, the isotherm approach used in this research allows for an empirically based analysis of whole-rock batch reactor sorption data that reflect whole-rock mineralogy and mineral surface chemistry while providing a means to rapidly assess sorption behavior from easily conducted batch reaction experiments.

\section{REFERENCES}

Al, T.A., C.J. Martin, and D.W. Blowes. 2000. Carbonate-mineral/ water interactions in sulfide-rich mine tailings. Geochim. Cosmochim. Acta 64:3933-3948.

Appelo, C.A.J., and D. Postma. 1993. Geochemistry, groundwater and pollution. A.A. Balkema, Brookfield, VT.

Appelo, C.A.J., M.J.J. van der Weiden, C. Tournassat, and L. Charlet. 2002. Surface complexation of ferrous iron and carbonate on ferrihydrite and the mobilization of arsenic. Environ. Sci. Technol. 36: 3096-3103.

Arai, Y., and D.L. Sparks. 2002. Residence time effects on arsenate surface speciation at the aluminumoxide-water interface. Soil Sci. 167:303-314.

Baedecker, P.A. 1987. Methods for geochemical analysis. Bull. 1170. USGS, Reston, VA.

Bartlett, R.W. 1992. Solution mining: Leaching and fluid recovery of materials. Gordon and Breach Science Publ., Philadelphia, PA.

Bethke, C.M., and P.V. Brady. 2000. How the Kd approach undermines ground water cleanup. Ground Water 38:435-443.

Bostick, B.C., and S. Fendorf. 2003. Arsenite sorption on troilite (FeS) and pyrite $\left(\mathrm{FeS}_{2}\right)$. Geochim. Cosmochim. Acta 67:909-921.

Bowell, R.J. 1994. Sorption of As by iron oxides and oxyhydroxides in soils. Appl. Geochem. 9:279-286.

Bowell, R.J., N.H. Morley, and V.K. Din. 1994. Arsenic speciation in soil porewaters from the Ashanti Mine, Ghana. Appl. Geochem. 9:15-22.

Charlet, L., and A. Manceau. 1994. Evidence for the neoformation of clays upon sorption of $\mathrm{Co}(\mathrm{II})$ and $\mathrm{Ni}(\mathrm{II})$ on silicates. Geochim. Cosmochim. Acta 58:2577-2582.

Communar, G., R. Keren, and L. FaHu. 2004. Deriving boron adsorption isotherms from soil column displacement experiments. Soil Sci. Soc. Am. J. 68:481-488.

Cornu, S., D. Breeze, A. Saada, and P. Baranger. 2003. The influence of $\mathrm{pH}$, electrolyte type, and surface coating on $\mathrm{As}(\mathrm{V})$ adsorption onto kaolinites. Soil Sci. Soc. Am. J. 67:1127-1132.

Davis, J.A., J.A. Coston, D.B. Kent, and C.C. Fuller. 1998. Application of the surface complexation concept to complex mineral assemblages. Environ. Sci. Technol. 32:2820-2828.

Decker, D.L., J. Šimůnek, S.W. Tyler, C. Papelis, and M. Logsdon. 2006. Variably saturated reactive transport of arsenic in heap-leach facilities. Available at www.vadosezonejournal.org. Vadose Zone J. 5: $\mathrm{xx}-\mathrm{xx}$ (this issue).

Dickson, F.W., R.O. Rye, and A.S. Radtke (ed.) 1979. The Carlin gold deposit as a product of rock-water interactions.

Driesner, D., and A. Coyner. 2000. Major mines in Nevada 1999. Nevada Bureau of Mines and Geology, Reno.

Dzombak, D.A., and F.M.M. Morel. 1990. Surface complexation modeling: Hydrous ferric oxide. John Wiley and Sons, New York.

Flynn, C.M., and S. McGill-Haslem. 1995. Cyanide chemistry-Precious metals processing and waste treatment. IC-9429. United States Department of Interior, Bureau of Mines. 
Furman, N.H. 1938. Scott's standard methods of chemical analysis: A manual of analytical methods and general reference for the analytical chemist and for the advanced student. Vol. 1. 5th ed. von Nostrand, New York.

Goldberg, S. 2002. Competitive adsorption of arsenate and arsenite on oxides and clay minerals. Soil Sci. Soc. Am. J. 66:413-421.

Goldberg, S., and R.A. Glaubig. 1988. Anion sorption on a calcareous, montmorillonitic soil-Arsenic. Soil Sci. Soc. Am. J. 52:1297-1300.

Goldberg, S., and C.T. Johnston. 2001. Mechanisms of arsenic adsorption on amorphous oxides evaluated using macroscopic measurements, vibrational spectroscopy, and surface complexation modeling. J. Colloid Interface Sci. 234:204-216.

Hingston, F.J., R.J. Atkinson, A.M. Posner, and J.P. Quirk. 1967. Specific adsorption of anions. Nature (London) 215:1459-1461.

Hingston, F.J., A.M. Posner, and J.P. Quirk. 1972. Anion adsorption by goethite and gibbsite. I. The role of the proton in determining adsorption envelopes. J. Soil Sci. 23:177-192.

Ho, Y.S., J.F. Porter, and G. McKay. 2002. Equilibrium isotherm studies for the sorption of divalent metal ions onto peat: Copper, nickel and lead single component systems. Water Air Soil Pollut. 141:1-33.

Jain, A., K.P. Raven, and R.H. Loeppert. 1999. Arsenite and arsenate adsorption on ferrihydride: Surface charge reduction and net $\mathrm{OH}^{-}$ release stoichiometry. Environ. Sci. Technol. 33:1179-1184.

Keren, R., and R.G. Gast. 1983. pH-dependent boron adsorption by montmorillonite hydroxy-aluminum complexes. Soil Sci. Soc. Am. J. 47:1116-1120.

Keren, R., R.G. Gast, and B. Bar-Yosef. 1981a. pH-dependent boron adsorption by Na-montmorillonite. Soil Sci. Soc. Am. J. 45:45-48.

Keren, R., R.G. Gast, and B. Bar-Yosef. 1981b. Errata: pH-dependent Boron adsorption by Na-Montmorillonite. Soil Sci. Soc. Am. J. 45:1006.

Keren, R., P.R. Grossi, and D.L. Sparks. 1994. Equilibrium and kinetics of borate adsorption-desorption on pyrophyllite in aqueous suspensions. Soil Sci. Soc. Am. J. 58:1116-1122.

Koretsky, C. 2000. The significance of surface complexation reactions in hydrologic systems: A geochemist's perspective. J. Hydrol. (Amsterdam) 230:127-171.

Le Guern, C., P. Baranger, C. Crouzet, F. Bodenan, and P. Conil. 2003. Arsenic trapping by iron oxyhydroxides and carbonates at hydrothermal spring outlets. Appl. Geochem. 18:1313-1323.

Lumsdon, D.G., J.C.L. Meeussen, E. Paterson, L.M. Garden, and P. Anderson. 2001. Use of solid phase characterization and chemical modeling for assessing the behavior of As in contaminated soils. Appl. Geochem. 16:571-581.

Manning, B.A., S.E. Fendorf, and S. Goldberg. 1998. Surface structures and stability of As(III) on goethite: Spectroscopic evidence for inner-sphere complexes. Environ. Sci. Technol. 32:2383-2388.

Manning, B.A., and S. Goldberg. 1996a. Modeling arsenate competitive adsorption on kaolinite, montmorillonite, and illite. Clays Clay Miner. 44:609-623.

Manning, B.A., and S. Goldberg. 1996b. Modeling competitive adsorption of arsenate with phosphate and molybdate on oxide minerals. Soil Sci. Soc. Am. J. 60:121-131.
Manning, B.A., and S. Goldberg. 1997a. Arsenic(III) and arsenic(V) adsorption on three California soils. Soil Sci. Soc. Am. J. 162: 886-895.

Manning, B.A., and S. Goldberg. 1997b. Adsorption and stability of As(III) at the clay mineral-water interface. Environ. Sci. Technol. 31:2005-2011.

Manning, B.A., and D.A. Martens. 1997. Speciation of As(III) and $\mathrm{As}(\mathrm{V})$ in sediment extracts by high-performance liquid chromatography-hydride generation atomic absorption spectrophotometry. Environ. Sci. Technol. 31:171-177.

Mezuman, U., and R. Keren. 1981. Boron adsorption by soils using a phenomenological adsorption equation. Soil Sci. Soc. Am. J. 45: $722-726$.

Nordstrom, D.K., and D.G. Archer. 2003. Arsenic thermodynamic data and environmental geochemistry. p. 1-25. In K.G. Stollenwerk (ed.) Arsenic in ground water. Kluwer Academic Publishers, Dordrecht, The Netherlands.

Pierce, M.L., and C.B. Moore. 1982. Adsorption of arsenite and arsenate on amorphous iron hydroxide. Water Res. 16:1247-1253.

Price, J.G. 2000. The Nevada mineral industry 1999. Nevada Bureau of Mines and Geology, Reno.

Rytuba, J.J. 1985. Geochemistry of hydrothermal transport and deposition of gold and sulfide minerals in Carlin-type gold deposits. p. 27-34. In E.W. Tooker (ed.) Geologic characteristics of sedimentand volcanic-hosted disseminated gold deposits-Search for an occurrence model. Bull. 1646. USGS, Reston, VA.

Shevenell, L.A., K.A. Connors, and C.D. Henry. 1999. Controls on pit lake water quality at sixteen open-pit mines in Nevada. Appl. Geochem. 14:669-687.

Singer, D.A. 1996. An analysis of Nevada's metal-bearing mineral resources. Open-file Rep. 96-2. Nevada Bureau of Mines and Geology, Reno.

Sips, R. 1950. On the structure of a catalyst surface. II. J. Chem. Phys. 18:1024-1026.

Stumm, W. 1992. Chemistry of the solid-water interface. Wiley Interscience, New York.

Stumm, W., R. Kummert, and L. Sigg. 1980. A ligand exchange model for the adsorption of inorganic and organic ligands at hydrous oxide interfaces. Croat. Chem. Acta 53:291-312.

Tempel, R.N., L.A. Shevenell, P. Lechler, and J.G. Price. 2000. Geochemical modeling approach to predicting arsenic concentrations in a mine pit lake. Appl. Geochem. 15:475-492.

Tooker, E.W. 1985. Geologic characteristics of sediment- and volcanichosted disseminated gold deposits: Search for an occurrence model. Bull. 1646. USGS, Reston, VA.

Um, W., and C. Papelis. 2003. Sorption mechanisms of $\mathrm{Sr}$ and $\mathrm{Pb}$ on zeolitized tuffs from the Nevada Test Site as a function of $\mathrm{pH}$ and ionic strength. Am. Mineral. 88:2028-2039.

Um, W., and C. Papelis. 2004. Metal ion sorption and desorption on zeolitized tuffs from the Nevada Test Site. Environ. Sci. Technol. 38: 496-502.

Welch, A.H., D.B. Westjohn, D.R. Helsel, and R.B. Wanty. 2000. Arsenic in ground water of the United States: Occurrence and geochemistry. Ground Water 38:589-604. 